\title{
PENGARUH DAYA DAN TORSI UNTUK PERFORMA SEBUAH MESIN
}

\section{EFFECT OF POWER AND TORQUE THE PERFORMANCE OF A MACHINE}

\author{
Daifir Rohman Nurdiansyah, Surya Aditya Putra, Rafidan Azimansyah,Bagus Dwi Kurniawan, Andhika \\ Dasilva Rustandy Putra.
}

\begin{abstract}
(Teknik Mesin, Universitas Muhammadiyah Jember) Email: Rafidan.az@ gmail.com
(Teknik Mesin, Universitas Muhammadiyah Jember) Email: suryaaditya3387@gmail.com

(Teknik Mesin, Universitas Muhammadiyah Jember) Email: dasilvaandhika@gmail.com

(Teknik Mesin, Universitas Muhammadiyah Jember) Email: daifirrohman2001@ gmail.com

(Teknik Mesin, Universitas Muhammadiyah Jember) Email: bajosjos@gmail.com
\end{abstract}

\begin{abstract}
Abstrak
Torsi menjadi pengetahuan yang wajib dimiliki bagi Anda pengendara sepeda motor. Pasalnya, dengan mengetahui arti istilah tersebut, maka Anda bisa menilai performa dan juga kinerja mesin motor pada spesifikasi tertentu. Torsi sendiri menjadi pertimbangan bagi yang ingin membeli sepeda motor baru sebagai alat transportasi, mengenai seperti apakah sepeda motor yang anda butuhkan. Secara umum daya berbanding lurus dengan luas piston sedang torsi berbanding lurus dengan volume langkah. Parameter tersebut relatif penting digunakan pada mesin yang berkemampuan kerja dengan variasi kecepatan operasi dan tingkat pembebanan
\end{abstract}

\begin{abstract}
Abstrack
.Torque is a must-have knowledge for motorcyclists. The reason is, by knowing the meaning of the term, then you can assess the performance and also the performance of the motor engine at certain specifications. Torque itself is a consideration for those who want to buy a new motorbike as a means of transportation, regarding what kind of motorbike you need. In general, power is directly proportional to the piston area, while torque is directly proportional to the stroke volume. These parameters are relatively important to use on machines that are capable of working with variations in operating speed and loading levels.
\end{abstract}
A. TUJUAN
1. Mahasiswa mampu menjelaskan mengenai daya dan torsi
2. Mahasiswa mampu menganalisis pengaruh daya dan torsi pada sebuah mesin
3. Mahasiswa mampu menganalisis kerja sistem

\section{B. LANDASAN TEORI}

Pengaruh daya dan torsi berfungsi untuk mengetahui pengaruh variasi pencampuran bahan bakar dan Ethanol terhadap daya dan torsi. Perfoma suatu mesin pada umumnya dapat dilihat dari tingkat torsi, daya, konsumsi bahan bakar. Pada umumnya untuk mengetahui performa suatu mesin dapat diketahui dari spesifikasi mesin dari produsen pembuat mesin tersebut.daya,torsi dan konsumsi bahan bakar pada suatu mesin dapat di analisis mrnggunakan mesin dynotest. Daya tertinggi pada motor modifikasi dan standar jelas berbeda.. Daya rata-rata motor modifikasi naik dibanding dengan daya rata-rata motor standar. 


\section{PROSEDUR}

(1.) Spesifikasi mesin antara lain meliputi angka kompresi, jenis bahan bakar, derajat pengapian, dan durasi katub. Bila angka kompresi telah ditentukan, nilai angka oktan bahan bakar tertentu pula. Premium mempunyai angka oktan lebih rendah dari pada pertamax. Seiring dengan kebijakan pemerintah untuk pengalihan konsumsi premium menjadi pertamax, perlu diteliti secara teknik bagaimana perubahan performa mesinnya.

Torsi merupakan Gaya tekan putar pada bagian yang berputar, sepeda motor digerakkan oleh torsi dari crankshaft. Torsi adalah ukuran kemampuan mesin untuk melakukan kerja atau bergerak. Besaran torsi adalah besaran turunan yang biasa digunakan untuk menghitung energi yang dihasilkan dari benda yang berputar pada porosnya. Satuan torsi biasanya dinyatakan dalam N.m (Newton meter). Adapun rumusnya adalah sebagai berikut :

$$
\mathrm{T}=\mathrm{F} \times \mathrm{r}
$$

di mana:

$\mathrm{T}=$ Torsi benda berputar $(N . m)$

$\mathrm{F}=$ Gaya $(\mathrm{N})$

$\mathrm{r}=$ Jarak benda ke pusat rotasi $(\mathrm{m})$

Lantaran ada torsi inilah yang mengakibatkan benda berputar pada porosnya, serta benda akan berhenti jika ada usaha melawan torsi dengan besar sama juga dengan arah yang berlawanan. pada motor bakar untuk tahu daya poros mesti di ketahui dahulu torsinya. Pengukuran torsi pada poros motor bakar memakai alat yang diberi nama Dinamometer. Prinsip kerja dari alat ini yaitu dengan berikan beban yang berlawanan pada arah putaran hingga putaran mendekati $0 \mathrm{rpm}$, Beban ini nilainya yaitu sama juga dengan torsi poros.[1]

(2.) Motor bakar merupakan salah satu mesin pembakaran dalam atau sering disebut dengan istilah internal combustion engine yaitu mesin yang mengubah energy panas menjadi mekanik, energy itu sendiri dapat diperoleh dari peruses pembakaran. Salah satu alat trasnprotasi kendaraan bermesin yang yang sederhana yang banyak digunakan pada saat ini adalah sepeda motor. Perbandingan kompresi merupakan suatu perbandingan antara besarnya volume total silinder dengan volume ruang bakar.volume total siinder adalah penjumlaha dari volume ruang bakar dan volume langkah. Volume ruang bakar adalah volume diatas torak pada titik mati atas (TMA). Volume langkah adalah volume di atas torak sewaktu torak ada pada titik mati bawah (TMB) sampai garis titik mati atas (TMA). Volume langkah merupakan hasil dari perkalian dari luas permukaan torak dan panjang langkah torak. Semakin besar diameter torak dan panjang langkah dari suatu mesin sepeda motor maka akan semakin besar volume langkahnya. Tingginya perbandingan kompresi menetukan besarnya tekanan pembakaran campuran bahan bakar dan udara didalam silinder. Crankshaft CG200 dipilih karena sangat cocok diaplikasikan pada mesin 4 langkah 160 CC yang memiliki kesamaan karakteristik pada bagian mesin dan mempermudah pemasangan tanpa harus merubah komponen-komponen mesin lainya. Crangkshaft atau (poros engkol) CG200 yang memiliki panjang langkah $62.2 \mathrm{~mm}$ lebih tinggi dari poros engkol standar milik mesin $160 \mathrm{CC}$ yang hanya memiliki panjang langkah $49.5 \mathrm{~mm}$ perbedaan dua tipe poros engkol ini sangat berpengaruh terhadap performa mesin, langkah stroke up yang lebih panjang akan memperoleh kompresi yang lebih maksimal.[2] 
(3.) meningkatkan tegangan yang terjadi pada kumparan sekunder. Sehingga pada penggunaan sistem pengapian CDI akan berpengaruh terhadap kesempurnaan pembakaran dan daya yang di hasilkan oleh mesin. Untuk mengatasi kelemahan dari CDI limiter (standar) ini dan akan untuk memperoleh performa mesin yang lebih optimal,pada saat ini banyak pabrikan CDI yang menawarkan CDI unlimiter (BRT powermax hyberband) sebagai pengganti cdi limiter.CDI unlimiter adalah CDI yang kerjanya tanpa ada batasan pengapian dan mampu melayani kerja mesin pada RPM tinggi tergantung dari seberapa kuat mesin sepeda motor tersebut berputar.Sehingga dengan tidak adanya batasan dalam pengapiannya diharapkan performa mesin akan mencapai performa yang maksimal.

Daya merupakan salah satu parameter dalam menentukan performa motor. Pengertian dari daya motor adalah besarnya kerja motor tadi selama waktu tertu. Satuan yang digunakan yaitu hp (horse power). Untuk menghitung besarnya daya motor 4 langkah dapat digunakan rumus: $P=2 \pi . n . T 6000(h p)$

Dimana:

$P=$ Daya motor $(\mathrm{hp})$

$n=$ Putaran mesin $(\mathrm{rpm})$

$T=$ Torsi $(\mathrm{Nm})$

Gaya tekan putar pada bagian yang berputar disebut torsi, sepeda motor digerakkan oleh torsi dari crankshaft. Torsi atau momen gaya adalah gaya untuk memutarkan suatu benda pada porosnya. Maka torsi bisa diibaratkan sebagai gaya putar terhadap suatu benda. Satuan yang digunakan yaitu $\mathrm{Nm}$ (Newton meter) atau $\mathrm{lbs} \mathrm{ft}$ ('pound feet). Dari definisi ini, maka rumus Torsi adalah: $T=P m$..A.L.ia $A T A U T=F x d$

Keterangan:

$\mathrm{T}=$ Torsi $(\mathrm{N}, \mathrm{m})$

$\mathrm{Pm}=$ Tekanan efektif rata-rata $(\mathrm{kgf} / \mathrm{cm} 2)$

$\mathrm{F}=$ Gaya (Newton)

$\mathrm{A}=$ Luas penampang silinder $(\mathrm{cm} 2)$

$\mathrm{d}=$ Jarak (meter)

$\mathrm{L}=$ Panjang langkah torak $(\mathrm{m})$

$\mathrm{i}=$ Jumlah silinder

$\mathrm{a}=$ Jumlah siklus perputaran, 4 tak $\mathrm{a}=2 .[3]$

\section{(4.) Perancangan Desain Rangka Mesin penghalus}

Perancangan dimulai dari pembuatan rangka yang akan dipakai untuk desain mesin penghalus. Perancangan dilakukan dengan tahap pertama yaitu berupa rangka dari besi yang dilas listrik membentuk suatu desain yang telah dibuat sebelumnya menggunakan PC (Personal Computer). Tahap kedua yaitu penggabungan antara alat dan bahan dalam rangka tersebut. Kompon Penghitungan Variasi Kecepatan RPM.

Pengujian ini dilakukan untuk mengetahui tingkat kecepatan mesin penghalus otomatis terhadap benda kerja. Benda kerja yang dipakai berjumlah 3 buah balok kayu berukuran awal panjang 3,5 cm dan masing-masing benda kerja mendapatkan kecepatan yang berbeda-beda. Yaitu kecepatan rendah dengan kecepatan 1100 RPM, kecepatan sedang 1300 RPM dan kecepatan tinggi 1500 RPM en yang dimaksud yaitu motor AC (Dynamo) 220 volt, bearing, as poros dan roll pemutar amplas. Penghitungan Tegangan Listrik yang Dibutuhkan Pada tahap ini di lakukan penghitungan voltase listrik yang dibutuhkan mesin penghalus pada kecepatan rendah, sedang dan tinggi. Pengujian ini dilakukan dalam waktu 1 menit. 
Pengujian Benda Kerja Sebelum dan Sesudah Diuji

Pada tahap ini penulis menggunakan benda kerja kayu berbentuk balok dengan ukuran panjang awal 3,5 cm. Benda kerja yang dipakai berjumlah 9 buah balok kayu dan dibagi menjadi 3 bagian.[4]

(5.) Motor bakar adalah mesin atau pesawat tenaga yang merupakan mesin kalor dengan menggunakan energi panas untuk melakukan kerja mekanik dengan merubah energi kimia dari bahan bakar menjadi energi panas (thermal) sehingga menghasilkan energi mekanik. Metode penelitian pada pengaruh penggunaan variasi bahan bakar pertamax, pertalite dan premium terhadap performa mesin motor

Waktu yang dibutuhkan peneliti dalam melakukan penelitian ini adalah kurang lebih 1 menit. Langkah - langkah pengujian daya dan torsi antara lain:

1. Letakkan kendaraan motor yang akan diuji diatas dynotest dengan posisi roda belakang menempel tepat diatas roller.

2. Pasang penahan pada roda depan dengan diperkuat dengan pengereman agar kendaraan tidak dapat bergerak

3. Nyalakan mesin

4. Atur putaran mesin hingga kondisi stationer, kemudian biarkan beberapa saat untuk pemanasan.

5. Untuk memperoleh nilai torsi pada masing-masing variasi putaran mesin, atur putaran mesin 3000 - 7000 pada pengujian diketiga jenis bahan bakar yang digunakan (premium, pertalite dan pertamax).

6. Untuk memperoleh nilai torsi maksimal, atur putaran mesin hingga nilai RPM maksimal yang dapat diperoleh mesin.

7. Nilai torsi dibaca pada instrumen dynotest.[5]

(6.) Bahan bakar merupakan setiap material yang dapat terbakar dan melepaskan energi. Bahan bakar secara umum terdiri dari hidrogen dan karbon dan dituliskan dengan rumus umum berupa CnHm (Muchammad, 2010:31). Bahan bakar merupakan material, zat atau benda yang digunakan dalam proses pembakaran untuk menghasilkan energi panas.

Di Indonesia sedang gencar dikembangkan bahan bakar alternatif, salah satunya adalah ethanol karena sumber bahan baku dari ethanol tidaklah susah. Indonesia merupakan negara tropis yang sangat cocok untuk menanam tanaman bahan baku ethanol seperti tebu dan ketela. Bahan baku dalam pembuatan ethanol bisa mengunakan ketela dan tetes tebu. Ethanol merupakan salah satu bahan bakar alternatif yang mempunyai kelebihan dibandingkan BBM. Ethanol dengan kadar alkohol 70\% memiliki angka oktan 118 (Joko Winarno, 2011), sementara pertalite yang dijual oleh Pertamina hanya memiliki angka oktan 90.[6]

(7.) Dari hasil penelitian ini dengan menggunakan variasi tekanan udara sebesar 3 bar, 4 bar dan 5 bar; waktu penyemprotan 4 detik, 8 detik, 12 detik; dan sudut penyemprotan $30^{\circ}$, $60^{\circ}$ dan $90^{\circ}$ maka dapat dilihat pada rafik dibawah ini bahwa tekanan udara memiliki pengaruh paling besar tehadap kekasaran permukaan hasil proses sand blasting.

Pada pembahasan sebelumnya telah didapatkan hasil kekasaran permukaan yang paling rendah yaitu pada percobaan I dengan tekanan 3 bar, waktu penyemprotan 4 detik dan sudut penyemprotan $30^{\circ}$ sebesar $42,66 \mu \mathrm{m}$. Namun kebersihan permukaan yang dihasilkan 
masih belum sesuai dengan standar yang hanya mencapai tingkat kebersihan SA 2.

Kebersihan yang sesuai standar minimal harus mencapai tingkat SA 2,5.[7]

(8.) Kawat dibutuhkan untuk membuat solenoid perlu untuk diteliti berdasarkan referensi yang ada, baik melalui buku-buku pustaka ataupun standarisasi yang berlaku.

Kawat enamel yang banyak dijumpai di pasaran lokal adalah kawat buatan Indonesia (PT. Sucaco, Tbk) dan buatan Jerman (Hellenic Cables, SA). Adapun buatan Malaysia dan China (Ningbo Jintian New Material Co, Ltd) tidak semua toko menjualnya.

Solenoid ini adalah kumparan yang terbuat dari kabel panjang yang dililitkan secara rapat, dan dapat diasumsikan bahwa panjangnya jauh lebih besar daripada diameternya. Panjang kumparan solenoid ideal tak terhingga dengan kabel yang saling berhimpit dalam lilitannya dan medan magnit di dalamnya adalah seragam dan pararel terhadap sumbu solenoid tersebut.

Nilai induksi magnet untuk solenoid ideal dapat dihitung dengan persamaan berikut

$\mathrm{B}=$ induksi magnet $($ Tesla $=\mathrm{Wb} / \mathrm{m} 2)$

$\mu=$ permeabilitas (Wb/A.m)

$\mathrm{H}=$ kuat medan magnet $(\mathrm{A} / \mathrm{m})$

$\mathrm{i}=$ kuat arus yang mengalir $(\mathrm{A})$

$\mathrm{n}=$ jumlah lilitan

lc $=$ panjang kumparan. $[8]$

(9.) Performa mesin motor bensin dapat ditingkatkan dengan cara: memperpanjang langkah torak , memperbesar diameter torak, mengubah inlet port dan outlet port menaikkan kompresi pada ruang bakar, atau mengubah waktu pembukaan port silinder dengan volume udara dan bahan bakar yang meningkat maka semakin mudah terjadi pembakaran.

Selain porting juga dilakukan overstroke yaitu memperbesar volume langkah dengan cara menambah panjang langkah piston. Perbandingan besar volume total silinder dengan volume ruang bakar adalah perbandingan kompresi. Volume total silinder merupakan jumlah volume ruang bakar dengan dan volume langkah. Volume langkah adalah hasil kali luas permukaan torak dan panjang lamgkah . Maka dengan memperbesar panjang langkah akan memperbesar volume langkah sehingga memperbesar perbandingan kompresi.[9]

(10.) Modifikasi sistem mekanisme katup dapat dilakukan dengan cara melakukan perubahan pada diameter base circle intake dan exhaust pada camshaft..Tujuan penelitian ini adalah untuk mengetahui pengaruh besar diameter base circle tehadap daya dan torsi pada sepeda motor 4 langkah.

pada camshaft standar menghasilkan daya sebesar 14.8 HP pada putaran $9205 \mathrm{rpm}$ dan Torsi maksimal sebesar 11.76 NM pada putaran $7918 \mathrm{rpm}$. Sedangkan camshaft racing menghasilkan daya sebesar $15.8 \mathrm{HP}$ pada putaran $9426 \mathrm{rpm}$ dan Torsi maksimal sebesar 12.49 NM pada putaran $8604 \mathrm{rpm}$.

Untuk meningkatkan kinerja yang maksimal pada mesin motor dibutuhkan daya dan torsi yang besar. Berikut adalah rumus untuk mencari daya dan torsi:

Rumus untuk mencari daya dengan menggunakan persamaan.

Dengan:

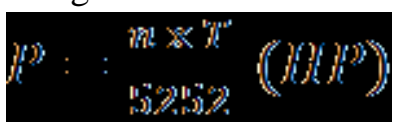


$\mathrm{P}=$ Daya $(\mathrm{HP})$

$\mathrm{n}=$ Putaran Mesin (rpm)

$\mathrm{T}=$ Torsi Mesin (N.m)

Rumus untuk mencari torsi dengan menggunakan persamaan

Dengan:

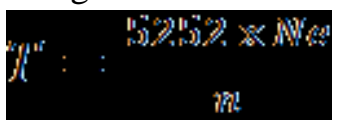

$\mathrm{T}=$ Torsi $(\mathrm{N} . \mathrm{m})$

$\mathrm{Ne}=$ Daya $(\mathrm{HP})$

$\mathrm{n}=$ Putaran mesin $(\mathrm{rpm})$

Kapasitas momen nominal struktur akibat tekuk torsi lateral dapat dihitung menggunakan persamaan berikut:

$M n=S c F c$

Dimana:

Mn adalah momen nominal akibat tekuk torsi lateral (Nmm).

Sc adalah modulus penampang elastis yang dihitung pada tegangan $\mathrm{Fc}$ pada serat tekan terluar (mm3).

Fc adalah tegangan kritis tekuk torsi lateral elastic atau inelastic (Mpa).

Nilai Fc dihitung berdasarkan kondisi seperti berikut:

Jika $F e \geq 2.78 F y$, maka $F C=F y$

Jika $2.78 F y>F e>0.56 F y$, maka $F c=109 F y(1-10 F y 36 F e)$

Jika $F e \leq 0.56 F y$, maka $F e \leq 0.56 F y$

Dimana:

Fe adalah tegangan kritis elastis tekuk torsi lateral (Mpa).

Tegangan kritis Fe dihitung berdasarkan bentuk profil yang digunakan. Untuk penampang bentuk I, Fe dihitung menggunakan persamaan berikut:

$F e=C b \pi 2 E d I y c S f L 2$

Sedangkan untuk penampang kotak tertutup (box sections, Fe dihitung berdasarkan persamaan berikut:

$F e=C b \pi L S f \sqrt{ } E I y G J$

Dimana:

$\mathrm{Cb}$ adalah koefisien yang tergantung pada distribusi momen pada segmen yang tidak dibresing secara lateral.

E adalah modulus Elastisitas (Mpa)

$\mathrm{d}$ adalah tinggi profil $(\mathrm{mm})$.

Iyc adalah momen inersia porsi tekan pada penampang (mm4).

Sf adalah modulus penampang elastis ( $\mathrm{mm} 3)$

$\mathrm{L}$ adalah panjang balok tanpa pengaku $(\mathrm{mm})$

Iy adalah momen inersia arah y (mm4).

$\mathrm{G}$ adalah modulus geser baja ringan (Mpa).

$\mathrm{J}$ adalah konstanta torsi untuk penampang.[10]

(11.) Untuk menghitung momen nominal akibat tekuk torsi lateral, nilai Fc ditentukan berdasarkan nilai Fe. Untuk profil back to back, nilai Fe dihitung berdasarkan persamaan 2.19 dengan tahapan perhitungan sebagai berikut: 
Perhitungan koefisien $\mathrm{Cb}$

$C b=12.5(429750) 2.5(429750)+3(188015,6)+4(322312,5)+3(402890,6)=1,299$

Perhitungan Iyc

a. Mencari nilai $\Sigma A . x 2$

\begin{tabular}{|c|c|c|c|c|}
\hline \multirow{2}{*}{ Elemen } & \multicolumn{2}{|l|}{ Luas (A) } & Jarak dari sumbu y $(\mathrm{x})$ & A. $x^{\wedge} 2$ \\
\hline & \multicolumn{2}{|l|}{$\mathrm{mm} 2$} & $\mathrm{~mm}$ & $\mathrm{~mm} 4$ \\
\hline Sayap & \multirow{3}{*}{$\begin{array}{r}4(\mathrm{w})(\mathrm{t}) \\
4(\text { A bengkokan) } \\
2(\mathrm{~h})(\mathrm{t})\end{array}$} & \multirow{3}{*}{$\begin{array}{l}=585.6 \\
=110.4616 \\
=537.6\end{array}$} & 30.6 & 548332.4 \\
\hline Bengkoka & & & 2.994 & 990.1156 \\
\hline Badan & & & 1.5 & 1209.6 \\
\hline Total & $\sum A=$ & 1233.662 & $\sum A \cdot x^{\wedge} 2=$ & 550532.1 \\
\hline
\end{tabular}

b. Mencari I sayap

I flanges $=4(t(w) 312)=4(3(48,8) 312)=116214,3 \mathrm{~mm} 4$

c. Mencari Iy

$I y=\Sigma A . x 2+$ Iflanges $=550532,1+116214,3=666746,4 \mathrm{~mm} 4$

d. Mencari Iyc

$I y c=I y 2=666746,42=333373,2 \mathrm{~mm} 4$

Perhitungan Sf

a. Mencari nilai $\Sigma A . y 2$

Tabel 3: Perhitungan $\Sigma$

\begin{tabular}{|c|c|c|c|c|}
\hline \multirow{2}{*}{ Elemen } & \multicolumn{2}{|l|}{ Luas (A) } & Jarak dari titik pusat (y) & A. $y^{\wedge} 2$ \\
\hline & \multicolumn{2}{|l|}{$\mathrm{mm} 2$} & $\mathrm{~mm}$ & $\mathrm{~mm} 4$ \\
\hline Sayap & \multirow{3}{*}{$\begin{array}{r}4(w)(t) \\
4(A \text { bengkokan }) \\
2(h)(t)\end{array}$} & \multirow{3}{*}{$\begin{array}{l}=585.6 \\
=110.46 \\
=537.6\end{array}$} & 49.5 & 1434866.4 \\
\hline Bengkokan & & & 47.794 & 252322.7 \\
\hline Badan & & & 0 & 0 \\
\hline Total & $\sum A$ & 1233.7 & $\sum A \cdot y^{\wedge} 2=$ & 1687189 \\
\hline
\end{tabular}

http://jurnal.sttgarut.ac.id/ 91

d. Mencari Iyc

$I y c=I y 2=666746,42=333373,2 \mathrm{~mm} 4$

Perhitungan Sf

a. Mencari nilai $\Sigma A . y 2 .[11]$

(12.) Torsi adalah ukuran kemampuan mesin untuk melakukan kerja, jadi torsi adalah suatu energi. Besaran torsi adalah besaran turunan yang biasa digunakan untuk menghitung energi yang dihasilkan dari benda yang berputar pada porosnya. Adapun perumusan dari torsi adalah sebagai berikut. Apabila suatu benda berputar dan mempunyai besar gaya sentrifugal sebesar $\mathrm{F}$, benda berputar pada porosnya dengan jari-jari sebesar $\mathrm{b}$, dengan data tersebut torsinya adalah:

$\mathrm{T}=\mathrm{F} \times \mathrm{d}(\mathrm{N} . \mathrm{m})$

dimana:

$\mathrm{T}=$ Torsi benda berputar (N.m)

$\mathrm{F}=$ adalah gaya sentrifugal dari benda yang berputar $(\mathrm{N})$

$\mathrm{d}=$ adalah jarak benda ke pusat rotasi $(\mathrm{m})$ 
Karena adanya torsi inilah yang menyebabkan benda berputar terhadap porosnya, dan benda akan berhenti apabila ada usaha melawan torsi dengan besar sama dengan arah yang berlawanan.

Pada motor bakar untuk mengetahui daya poros harus diketahui dulu torsinya. Pengukuran torsi pada poros motor bakar menggunakan alat yang dinamakan Dynotest. Hasil Pengujian pada sepeda motor yang menggunakan katup standar dan katup modifikasi dengan menggunakan alat pengujian yaitu dynotest dengan mengukur torsi sepeda motor.[12]

(13) Motor universal adalah motor arus bolak balik yang memiliki konstruksi maupun karakteristiksama dengan motor arus searah. Motor Universal termasuk motor satu phasa dengan menggunakan belitan stator dan belitan rotor.

Daya listrik atau dalam bahasa Inggris disebut dengan Electrical Power adalah jumlah energi yang diserap atau dihasilkan dalam sebuah sirkuit/rangkaian.

Torsi adalah gaya pada gerak translasi menunjukkan kemampuan sebuah gaya untuk Membuat benda melakukan gerak rotasi/berputar. Sebuah benda akan berotasi bila dikenai torsi. Satuan yang sering digunakan adalah Newtonmeter $(\mathrm{Nm})$. Torsi pada motor listrik dapat diperoleh dari hasil bagi antara daya keluaran (Watt) dengan kecepatan motor (rpm).[13]

(14.) Octane booster dapat mempengaruhi terhadap bahan bakar dan menghasilkanperformance pada suatu kendaraan karena octane booster proses pembakaran yang sempurna.

Angka oktan adalah angka yang menunjukkan seberapa besar tekanan yang bisa diberikan sebelum bensin terbakar secara spontan. Angka oktan (octane number) atau tingkatan dari bahan bakar adalah mengukur bahan bakar bensin terhadap anti-knock charesteristic. Bensin dengan angka oktan tinggi akan tahan terhadap timbulnya engine knocking dibanding dengan angka oktan yang rendah.

Aditif Octane Booster merupakan komponen dari senyawa yang digunakan untuk meningkatkan angka oktan dari bahan bakar dan sekaligus sebagai booster komponen anti ketuk. yang berasal dari amerika.[14]

(15.) pengujian tentang perbandingan performa mesin yang meliputi torsi, daya, laju konsumsi bahan bakar, specific fuel consumption, dan efisiensi berbahan bakar LPG dan premium pada mesin sepeda motor.

Adapun langkah-langkah pengujian adalah sebagai berikut:

1. Menghidupkan mesin selama 5 menit sebagai pemanasan untuk mencapai kondisi kerja yang diinginkan. Dalam kondisi ini mesin tidak terbebani sama sekali..

2. Ketika putaran maksimum untuk bukaan throltle gas 7000 rpm telah tercapai lakukan pengereman hingga mencapai $6000 \mathrm{rpm}$, catat beban yang tampil pada load display, kemudian lepaskan rem dan biarkan hingga mencapai putaran maksimum lagi.

3. Untuk putaran 6000 - 3000 rpm dilakukan sama seperti langkah no. 3 dan begitu juga seterusnya.

4. Melakukan pengukuran konsumsi bahan bakar. Dengan cara;

Konsumsi Premium :

- Isi gelas ukur dengan premium sebanyak $50 \mathrm{ml}$.

- Kemudian catat hasil pemakaian bahan bakar per 2 menit. 
- Untuk menghitung Laju aliranya, dengan cara mengalikan dengan masa jenis bahan bakar. Konsumsi gas LPG :

- Letakan pada timbangan digital catat berat bersih gas setelah dikurangi berat tabung.

- Kemudian catat per 2 menit penyusutanya yang tertera pada timbangan digital.

- Mematikan mesin setelah steady sekitar 3-5 menit temperaturnya turun sekitar $40-45^{\circ} \mathrm{C}$. Perhitungan torsi maksimal pada putaran $4000 \mathrm{rpm}$ dengan nilai $18,18 \mathrm{Nm}$ untuk bahan bakar premium. torsi maksimal bahan bakar LPG terjadi pada putaran $4000 \mathrm{rpm}$ dengan nilai $16,95 \mathrm{Nm}$. pemakaian bahan bakar LPG tidak dapat diterapkan langsung pada mesin bahan bakar premium karena terjadi penurunan torsi.

Perhitungan daya pengereman tertingi bahan bakar premium terjadi pada putaran $5000 \mathrm{rpm}$ dengan nilai $2,30 \mathrm{~kW}$. sedangkan daya pengereman tertingi bahan bakar LPG terjadi pada putaran $5000 \mathrm{rpm}$ dengan nilai $2,18 \mathrm{~kW}$.

Nilai Air Ful Ratio (AFR) akan menurun seiring dengan kenaikan rpm. pada rpm tinggi energi yang dibutuhkan untuk menghasilkan torsi sangat kecil sehingga bahan bakar yang digunakan semakin sedikit. AFR merupakan perbandingan antara laju aliran massa udara ( $m a$ ) dengan laju aliran massa bahan bakar ( $m f$ ). AFR ini adalah AFR aktual yang digunakan untuk mencari AFR relatif dengan cara membagi AFR aktual dengan AFR stoikiometris. Secara umum bahan bakar premium memiliki effisiensi yang lebih baik dari bahan bakar LPG.[15]

\section{KESIMPULAN}

1. Daya atau dalam bahasa Inggris disebut dengan Power adalah jumlah energi yang diserap atau dihasilkan dalam sebuah rangkaian. Sumber Energi seperti Tegangan listrik akanmenghasilkan daya listrik sedangkan beban yang terhubung dengannyaakan menyerap daya listrik tersebut. Dengan kata lain, Daya listrik adalahtingkat konsumsi energi dalam sebuah sirkuit atau rangkaian listrik.Semakin tinggi nilai Watt-nya semakin tinggi pula daya listrik yangdikonsumsinya.

2. Torsi juga disebut momen, diawali darikerja Archimedes dalam lever. Informalnya, torsi dapat dipikirsebagai gaya rotasional. Analog rotational dari gaya, masa,dan percepatan adalah torsi, momen inertia dan percepatanangular. Gaya yang bekerja pada lever, dikalikan dengan jarak dari titiktengah lever, adalah torsi.

3. Torsi dan daya itu saling berhubungan karna merupakan suatu terpenting untuk mengetahui performa sebuah mesin, bukan hanya mesin motor melainkan semua mesin yang bisa berjalan atau bergerak. Dan berguna sebagai ilmu yang penting terutama untuk orang yang hobi akan sebuah mesin atau penelitian mengenai performa sebuah mesin.

\section{E. DAFTAR PUSTAKA}

[1] N. Ana Mufarida, A. Fathoniyam Putra Nusantara, and J. Teknik Mesin, "PENGARUH MODIFIKASI LIFT CAMSHAFT TERHADAP PERFORMA MOTOR 4 TAK 100CC The Effect of Camshaft Lift Modification on the Performance of 100cc Motorbike," 2017.

[2] N. Ana Mufarida and D. Pembimbing, "PENGARUH UNJUK KERJA (STROKE UP) TERHADAP PERFORMA MESIN PADA MOTOR 4 LANGKAH YANG MENGGUNAKAN VARIASI (CRANKSHAFT CG200) EFFECT OF PERFORMANCE(STROKEUP)ON PERFORMANCE MACHINE 4 STEP MOTOR USING THE VARIATIONS (CG200 CRANKSHAFT)," 2018. 
[3] I. Tri Wahyulianto Putra et al., "PERBANDINGAN CDI STANDAR DAN CDI VARIASI TERHADAP PERFORMA MOTOR 4 TAK 100 CC COMPARISON STANDARD CDI AND VARIATIONS TO MOTORCYCLE PERFORMANCE 4 TAK 100 CC," 2018.

[4] M. Hasan Noval et al., "EFFECT OF VARIATION TO MOTORCYCLE ON ENTERPRISE SURFACE TYPES OF DISC AND BELT ON SURFACE BOTTLESENCE OF WORKING OBJECTS," 2018.

[5] "j pro5".

[6] "j pro6".

[7] A. Kekerasan, D. Dwilaksana, G. Jatisukamto, and J. Teknik Mesin, "Surface Roughness Analysis of Sand Blasting Process with Variation of Pressure, Time, and Angle using Taguchi Method," J-Proteksion, vol. 2, no. 1, pp. 27-30, 2017.

[8] N. Sinaga and M. H. Sonda, "PEMILIHAN KAWAT ENAMEL UNTUK PEMBUATAN SOLENOID DINAMOMETER ARUS EDDY DENGAN TORSI MAKSIMUM 496 Nm,” 2013.

[9] F. Majedi and I. Puspitasari, "Optimasi Daya dan Torsi pada Motor 4 Tak dengan Modifikasi Crankshaft dan Porting pada Cylinder Head," 2017.

[10] M. S. Ghaly, Y. Agus Winoko, T. Mesin, and P. N. Malang, "Analisis Perubahan Diameter Base Circle Camshaft Terhadap Daya Dan Torsi Pada Sepeda Motor," Jurnal Flywheel, vol. 10, no. 2, 2019, [Online]. Available: https://infobalapliarjakarta.blogspot.co.id

[11] F. Padhlurohman and E. Walujodjati, "Analisis Kapasitas Balok Baja Ringan Menahan Tekuk Torsi Lateral.” [Online]. Available: http://jurnal.sttgarut.ac.id/

[12] M. D. Rahman, N. Arya Wigraha, G. Widayana, and A. C. Id, "Pengaruh Ukuran Katup Terhadap Torsi Dan Daya Pada Sepeda Motor Honda Supra Fit," 2017.

[13] P. Katolik, P. Sorong, J. Teknik, M. Politeknik, and K. Saint, "ANALISIS PERBANDINGAN DAYA DAN TORSI PADA ALAT PEMOTONG RUMPUT ELEKTRIK (APRE) SURIANTO BUYUNG," 2018.

[14] "document".

[15] M. Waris Sudrajat, "PENGGUNAAN BAHAN BAKAR GAS PADA MESIN SEPEDA MOTOR DITINJAU DARI ASPEK DAYA dan TORSI,” 2014. 